\title{
GMR
}

\section{Relationship between serum leptin levels and non-small cell lung carcinoma: a meta-analysis}

\author{
J. Du*, J.C. Han*, Y.J. Zhang, G.B. Qi, Y. Zhang and H.B. Li \\ Department of Respiration, Huaihe Hospital of Henan University, Kaifeng, China \\ *These authors contributed equally to this study. \\ Corresponding author: J.C. Han \\ E-mail: hanjichang1231@163.com
}

Genet. Mol. Res. 14 (4): 13699-13708 (2015)

Received June 4, 2015

Accepted August 18, 2015

Published October 28, 2015

DOI http://dx.doi.org/10.4238/2015.October.28.32

ABSTRACT. In this study, we analyzed the association between serum leptin levels and non-small cell lung carcinoma (NSCLC). By examining English and Chinese databases, we identified potential relevant studies for statistical analysis. Human-associated case-control studies evaluating the association between serum leptin levels and NSCLC according to the random-effect model were retrieved and extracted data were statistically analyzed. We identified 7 case-control studies evaluating the correlation between serum leptin levels and NSCLC, which included 705 subjects (390 NSCLC patients and 315 healthy participants). Negative associations were investigated between serum leptin levels and NSCLC [standardized mean difference $(\mathrm{SMD})=0.96,95 \%$ confidence interval $(\mathrm{Cl})=0.13-1.79, \mathrm{P}=$ $0.023)$. Ethnicity-stratified analysis revealed there was no elevated leptin serum levels in NSCLC development in both Asians $(\mathrm{SMD}=0.34,95 \% \mathrm{Cl}$ $=-0.10-0.79, \mathrm{P}=0.132)$ and Caucasians $(\mathrm{SMD}=1.42,95 \% \mathrm{Cl}=-0.09$ $2.93, P=0.064)$. Sample size-stratified analysis of the association between serum leptin levels and NSCLC were found in studies of small sample size $(\mathrm{SMD}=0.73,95 \% \mathrm{Cl}=0.04-1.41, \mathrm{P}=0.038)$, but not in studies of large sample size $(\mathrm{SMD}=1.24,95 \% \mathrm{Cl}=-0.52-3.01, \mathrm{P}=0.166)$. In the method- 
stratified subgroup analysis, serum leptin level was not correlated with NSCLC using a immunoradiometric assay method $(\mathrm{SMD}=0.82,95 \% \mathrm{Cl}=$ -1.38-3.03, $P=0.465)$. Determining the levels of the blood-based marker leptin may provide predictive information for NSCLC diagnosis.

Key words: Blood test; Leptin; Meta-analysis; Serum levels; Non-small cell lung carcinoma; Standardized mean differences

\section{INTRODUCTION}

Non-small-cell lung carcinoma (NSCLC), composed of squamous cell carcinoma, lung adenocarcinoma, and large cell carcinoma, refers to any type of epithelial lung cancer resulting from cumulative disruption of the normal molecular programs responsible for modulating the growth and survival of the lung epithelium (Al-Wadei et al., 2012; Looyenga et al., 2012). NSCLC constitutes approximately $85 \%$ of all cases of lung carcinoma and is the most lethal cancer globally (Molina et al., 2008; Duan et al., 2013). As the most common type of lung carcinoma, NSCLC is estimated to cause over 1,000,000 deaths worldwide per year (Alifano and Damotte, 2013). Complicated in its nature, the etiology of NSCLC appears to aggregate a number of environmental stimuli and inherent determinants (Terzidis et al., 2009; Ettinger et al., 2010). The main risk factors for NSCLC include smoking, drinking, exposure to asbestos and radon, family history, and air pollution (Walker, 2008; Ettinger et al., 2012). Recently, the expression of leptin, an adipocyte-derived signaling factor, has been observed in human lung tissues (Vernooy et al., 2009; Vernooy et al., 2013). Furthermore, a variety of studies have implicated serum leptin levels in the pathogenesis of NSCLC (Terzidis et al., 2009; Song et al., 2014).

Leptin, a $16-\mathrm{kDa}$ pleiotropic molecule, belongs to the cytokine receptor family and is generated mainly by fat cells (Alemán et al., 2002; Yingzhong et al., 2006). In general, leptin possesses the ability to suppress food intake, regulate weight balance, and facilitate energy metabolism, as well as play a proliferative and an anti-apoptotic role in various processes such as lung carcinoma (Frühbeck, 2006; Carpagnano et al., 2007; Terzidis et al., 2009). In addition, leptin exerts its function through its receptors, which are thought to be secreted by a variety of cells originating from diverse tissues including the lung (Bruno et al., 2005; Lang and Ratke, 2009). Leptin receptors modulate innate and adaptive immune responses and are expressed in the respiratory epithelium, activated lymphocytes, and sub-mucosal space in the lung (Bruno et al., 2005; Vernooy et al., 2010). Serum leptin levels were shown to be decreased in patients with NSCLC, indicating that leptin is involved in NSCLC carcinogenesis (Jamieson et al., 2004; Karapanagiotou et al., 2011). Serum levels of leptin are closely linked to total fat mass and fat cell volume, and are typically lower in males than in females (Thomas et al., 2000). Specifically, leptin can reduce food intake and up-regulate energy consumption by inducing anorexigenic factors and inhibiting orexigenic neuropeptides (Lago et al., 2007). More importantly, reduced serum levels of leptin in NSCLC patients with weight loss may be explained by the hypothesis that leptin synthesis decreases in more advanced stages of carcinomas because of decreased fat mass resulting from cachexia (Jamieson et al., 2004; Ntikoudi et al., 2014). In contrast, leptin has an indirect effect on lung diseases by influencing sympathetic outflow and immune modulation, indicating that leptin has an important impact on not only the structure but also 
the function of the respiratory system (Faggioni et al., 2001). Thus, serum leptin levels may be correlated with the pathogenesis of NSCLC. Previous studies have found that serum levels of leptin were higher in healthy controls than in NSCLC patients, implying that reduced serum leptin levels may be related to NSCLC development (Jamieson et al., 2004; Tas et al., 2005), while opposite results were also reported by other researchers (Gulen et al., 2012; Lu et al., 2012). Therefore, we conducted this meta-analysis to clarify the association between serum leptin levels and NSCLC pathogenesis.

\section{MATERIAL AND METHODS}

\section{Search strategy}

Relevant articles were identified through a comprehensive online search of the following common databases: PubMed (1966-2014), MEDLINE (1966-2014), EMBASE (19992014), Cochrane (2005-2014), ISI Web of Science (1990-2014), Chinese National Knowledge Infrastructure (1990-2014), and WANFANG DATA (1990-2014). The last search was in May, 2014. Search terms for Leptin and NSCLC included ("Leptin”, "leptin”, "Obese Protein”, "Obese Gene Product”, “ Ob Gene Product”, "Ob Protein”) and (“lung neoplasms”, "lung cancer”, "lung carcinoma”, "pulmonary carcinoma”, "pulmonary cancer", "pulmonary neoplasms", "lung tumor", "pulmonary tumor"). There were no language restrictions used in the search, and necessary translation was performed. All titles and abstracts of retrieved articles were carefully screened and the full texts were obtained. A manual search of the reference lists of articles were combined in the search strategy with additional articles also searched.

\section{Inclusion and exclusion criteria}

Studies meeting the following criteria were included: 1) published as full-text and leptin serum level was detected from NSCLC patients and healthy controls; 2) the number of included patients was more than $10 ; 3$ ) all NSCLC patients were identified by histopathologic examinations; 4 ) if there were more than 2 overlapping patients samples, the largest relevant group size was selected; 5) studies were restricted to human populations and published in a peer-reviewed journal; 6) original data and sufficient information were provided regarding leptin serum levels in the NSCLC patients and healthy groups. Studies were excluded if they could not satisfy the above acquirements.

\section{Data extraction}

The following study information was collected in a standardized data form: surname and initials of the first author, publication year or submission year, source country and ethnicity, language of publication, sample size, gender, age of subjects, and leptin concentration ( $\mathrm{ng} / \mathrm{mL}) \mathrm{in}$ the serum of NSCLC patients and normal subjects.

\section{Statistical analysis}

All statistical analyses were conducted using STATA statistical software (Version 12.0, Stata Corporation, College Station, TX, USA). The mean value and standardized mean 
differences (SMD) for leptin serum level and the $95 \%$ confidence interval $(95 \% \mathrm{Cl})$ were used to estimate the relationship between leptin serum level and NSCLC development. The Cochran's Q-statistic and $l^{2}$ tests were used to calculate heterogeneity between NSCLC patients and normal samples included (Zintzaras and loannidis, 2005a). A random-effects model was applied if the Q-test showed a $\mathrm{P}<0.05$ or if the $I^{2}$ test was $>50 \%$, otherwise the fixed-effects model was applied (Higgins and Thompson, 2002; Zintzaras and loannidis, 2005b). Subgroup analysis was conducted if substantial heterogeneity was found in the serum level of leptin in NSCLC patients. Additionally, a one-way sensitivity analysis was applied to evaluate the effect of single studies on the overall estimate. Furthermore, potential publication bias was detected by Egger's linear regression test with $\mathrm{P}<0.05$ demonstrating a significant influence (Song and Gilbody, 1998; Peters et al., 2006).

\section{RESULTS}

\section{Description of included studies}

A combined search involving electronic database searching and manual searching were applied initially to search the possible articles, and 142 articles were identified. One duplicated study was removed. A total of 16 articles were excluded because of un-required article types, 27 were excluded article because they were not human studies, and 39 articles were unrelated to the research topic. A total of 59 articles remained for full-text evaluation and only 10 articles were suitable for qualitative analysis. Three studies lacked data integrity and were excluded. Finally, 7 case-control studies including 705 cases with 390 NSCLC patients and 315 healthy participants were used in the meta-analysis. The sample size of the final included studies varied from 33198 participants. Publication years ranged from 2003-2013. Three studies were conducted in Asians with 1 in China and 2 in Turkey, and 4 studies were in Caucasians in 4 different countries, including Greece, the US, UK, and Spain. The detection methods included enzyme-linked immunosorbent assay, radioimmunoassay, and immunoradiometric assay. The serum leptin level in NSCLC patients and normal participants were expressed as the mean \pm SD (Table 1).

\begin{tabular}{|c|c|c|c|c|c|c|c|c|c|c|c|}
\hline \multirow[t]{2}{*}{ First author } & \multirow[t]{2}{*}{ Year } & \multirow[t]{2}{*}{ Country } & \multirow[t]{2}{*}{ Ethnicity } & \multirow[t]{2}{*}{ Sample size } & \multicolumn{2}{|c|}{ Sample size } & \multicolumn{2}{|c|}{ Gender (M/F) } & \multicolumn{2}{|c|}{ Age (years) } & \multirow[t]{2}{*}{ Method } \\
\hline & & & & & Case & Control & Case & Control & Case & Control & \\
\hline Hong & 2013 & China & Asians & Small & 41 & 51 & $28 / 13$ & $32 / 19$ & $51.6 \pm 10.4$ & $46.7 \pm 10.5$ & ELISA \\
\hline Gulen & 2011 & Turkey & Asians & Small & 63 & 25 & $63 / 0$ & $25 / 0$ & $65.6 \pm 9.9$ & $63.5 \pm 11.5$ & ELISA \\
\hline Karapanagiotou & 2011 & Greece & Caucasians & Large & 96 & 49 & $79 / 17$ & $24 / 25$ & $64.3 \pm 10.6$ & $55.5 \pm 9.2$ & ELISA \\
\hline Terzidis & 2009 & USA & Caucasians & Large & 66 & 132 & $60 / 6$ & $120 / 12$ & $64.1 \pm 10.4$ & $64.3 \pm 10.7$ & RIA \\
\hline Tas & 2009 & Turkey & Asians & Small & 28 & 15 & $26 / 2$ & - & $65(41 \sim 80)$ & - & ELISA \\
\hline Jamieson & 2005 & UK & Caucasians & Small & 20 & 13 & $13 / 7$ & $6 / 7$ & 64 (43 79) & 65 (46 74) & RIA \\
\hline Aleman & 2003 & Spain & Caucasians & Large & 76 & 30 & $67 / 9$ & $26 / 4$ & 63 (36 75) & 59 (38 75) & IRMA \\
\hline
\end{tabular}

M: male; F: female; ELISA: enzyme linked immunosorbent assay; RIA: radioimmunoassay; IRMA: inmunoradiometric assay.

\section{Impact of leptin serum level on the development of NSCLC}

Random-effects analysis was used when $l^{2}>50 \%$ and $\mathrm{P}<0.001$ for the main meta- 
analysis and for subgroup analysis of the 3 groups. Significant differences in serum level of leptin were detected between the control and case groups in the meta-analysis. Leptin serum level was significantly lower in the NSCLC group than in the healthy group according to random effects analysis incorporating the SMD and $95 \% \mathrm{Cl}$ of the 7 studies $(\mathrm{SMD}=0.96,95 \% \mathrm{Cl}=0.13-1.79, \mathrm{P}$ $=0.023$ ) (Figure 1). Furthermore, stratified studies based on ethnicity, sample size, and detection methods were performed to explore the potential influential factors. Ethnicity stratified analysis revealed there was no elevated leptin serum level in NSCLC development in both Asians and Caucasians (Asians: $\mathrm{SMD}=0.34,95 \% \mathrm{Cl}=-0.10-0.79, \mathrm{P}=0.132$; Caucasians: $\mathrm{SMD}=1.42$, $95 \% \mathrm{Cl}=-0.09-2.93, \mathrm{P}=0.064)$. For sample size-stratified analysis, a clear relationship between leptin serum and NSCLC were found in the small sample size (SMD $=0.73,95 \% \mathrm{Cl}=0.04-1.41$, $P=0.038)$, but not in the large sample size $(S M D=1.24,95 \% C l=-0.52-3.01, P=0.166)$. The detection method-based subgroup analysis showed significant relationship between the enzymelinked immunosorbent assay and radioimmunoassay detection methods (all $P<0.05$ ), but the relationship was not affected by the immunoradiometric assay detection method $(\mathrm{SMD}=0.82$, $95 \% \mathrm{Cl}=-1.38-3.03, \mathrm{P}=0.465$ ) (Figure 2).

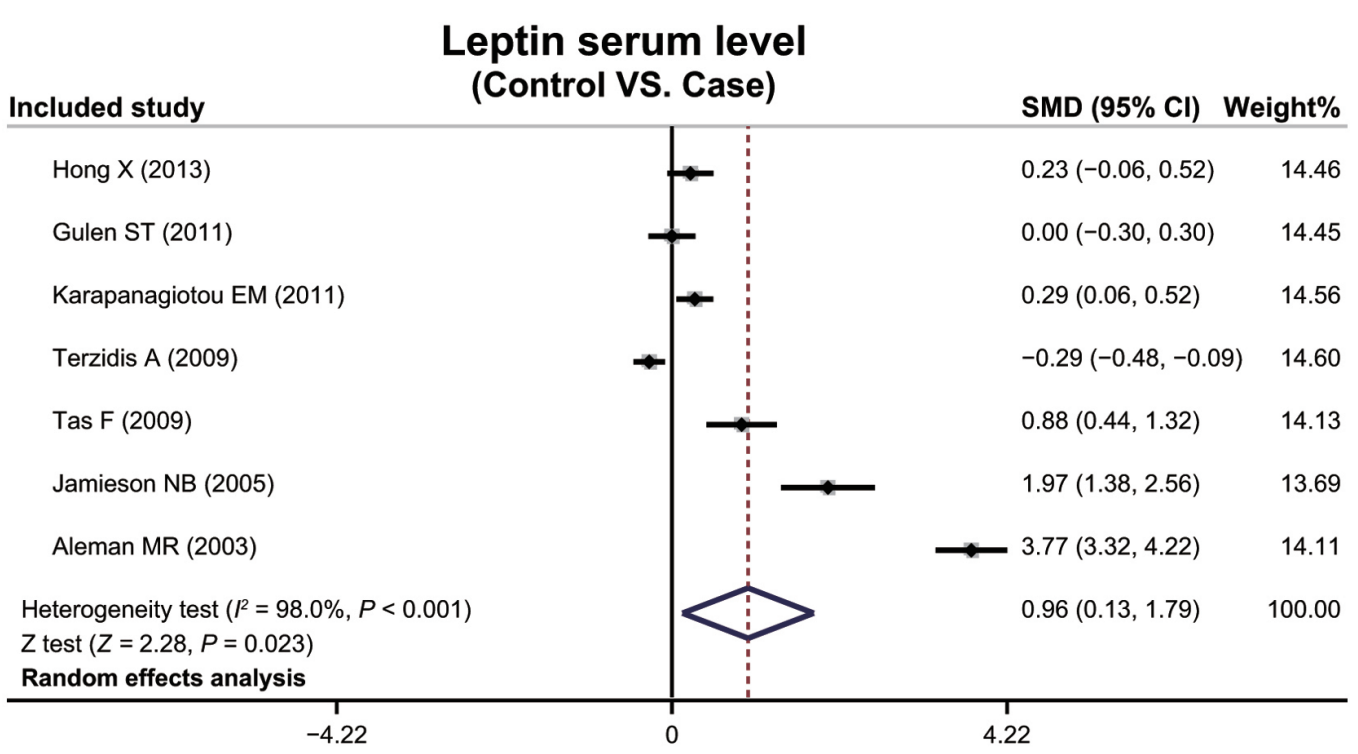

Figure 1. Forest plots showing the relationship between serum leptin levels and non-small cell lung carcinoma.

\section{Sensitivity analysis and publication bias}

Sensitivity analysis was conducted to determine the reliability of our results. We analyzed whether the overall results were affected by a single study and found that pooled SMDs were not affected by removing one study from the meta-analysis (Figure 3). Finally, the Egger's regression test showed an asymmetrical distribution in the funnel-plot of leptin serum levels in NSCLC patients and normal subjects, indicating publication bias in the systematic reviews (Egger's test: $t=2.76$, $P=0.040$ ) (Figure 4). 

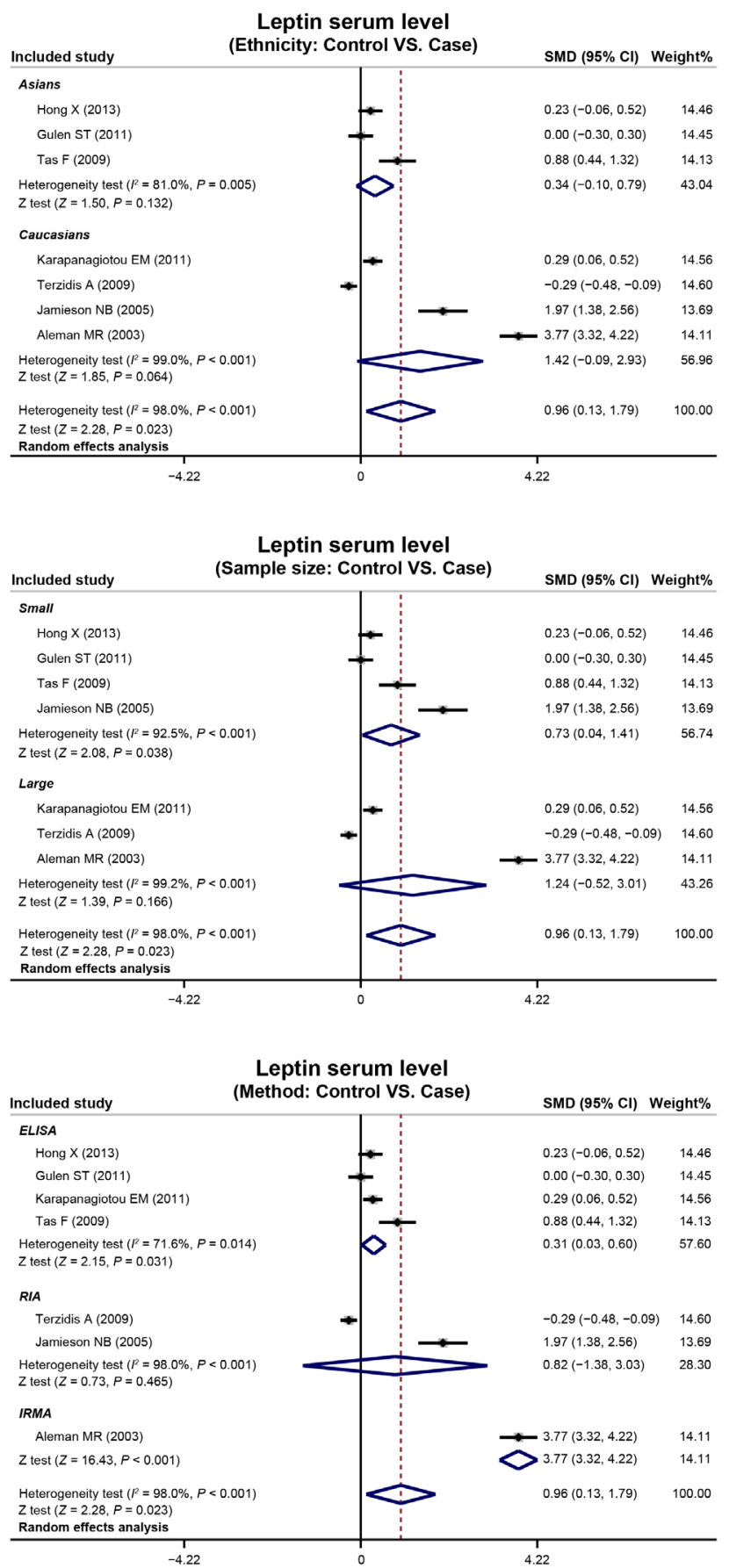

Figure 2. Subgroup analyses by ethnicity, sample size, and method for the relationship between serum leptin levels and non-small cell lung carcinoma. 


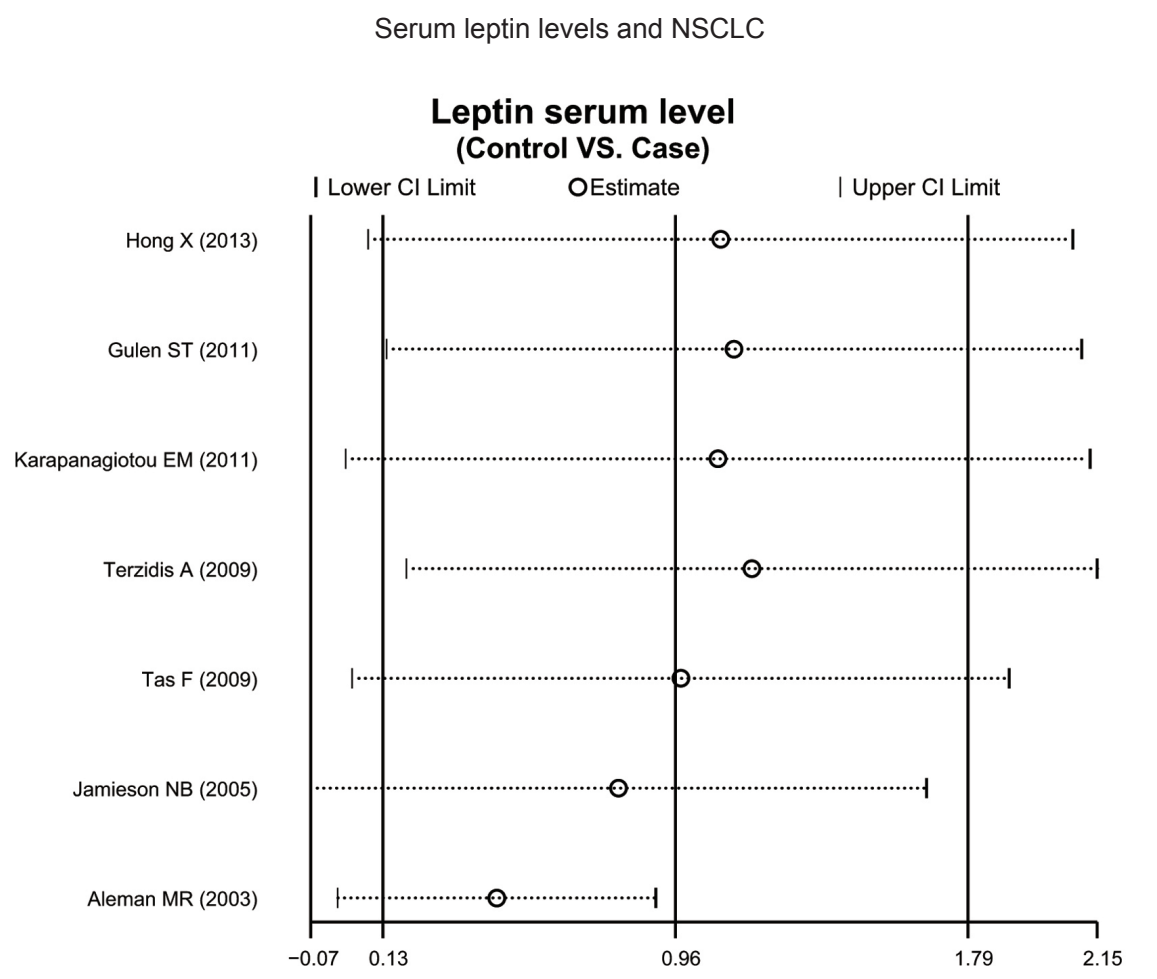

Figure 3. Sensitivity analysis of the relationship between serum leptin levels and non-small cell lung carcinoma.

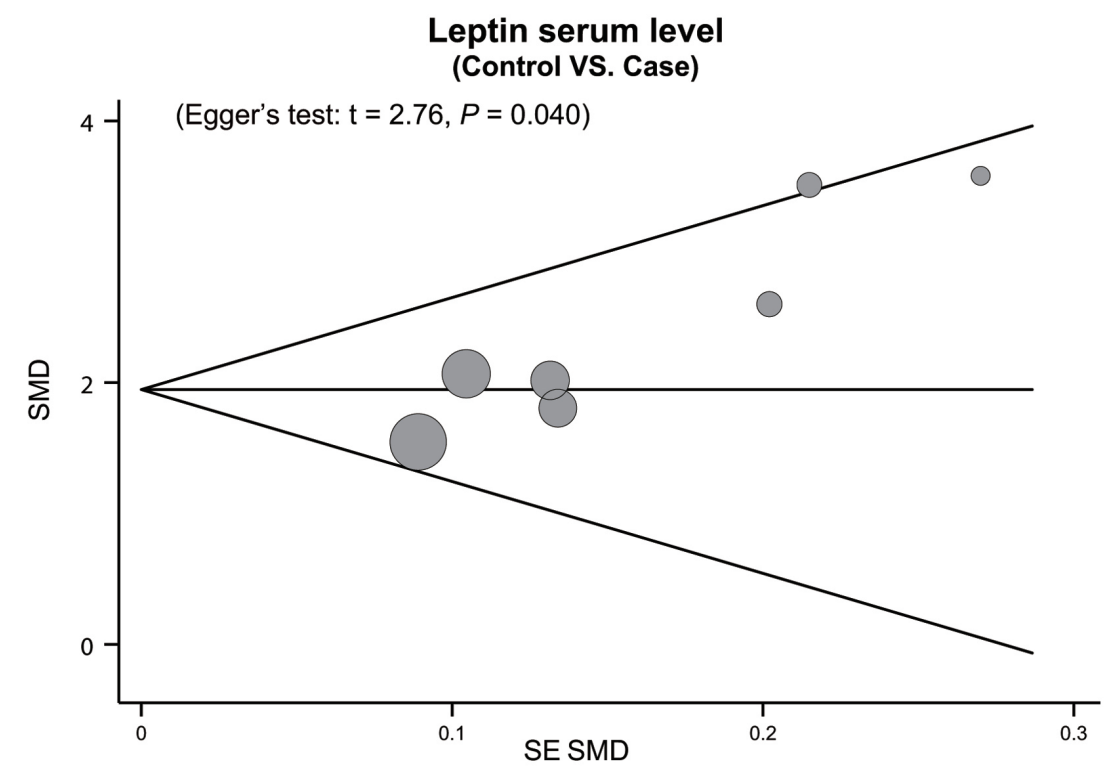

Figure 4. Funnel plot showing effect of publication biases on the correlation between serum leptin levels and non-small cell lung carcinoma. 


\section{DISCUSSION}

The relationship between leptin serum level and NSCLC development was explored in our meta-analysis. Our analysis showed a significant relationship between lower leptin serum level and NSCLC patients. Leptin, mainly produced by adipocytes, may participate in energy expenditure and food intake reduction by binding to Ob-Rb, a leptin receptor, to stimulate the receptor Tyr phosphorylation; this can activate the intracellular signal transducer JAK2 and STAT3 pathway (Farooq et al., 2014). Additionally, leptin has been reported to be involved in the inflammatory process by increasing the $\mathrm{TH} 1$ cytokine production and vascular endothelial growth factor release and suppressing the $\mathrm{TH} 1$ cytokines production to promote neutrophil chemotaxis and activation as well as increase natural killer cell cytotoxicity (Ali Assad and Sood, 2012; van den Borst et al., 2012). A previous study reported that the role of leptin in the process of inflammation may be associated with airway allergic diseases such as asthma and the lung development of intrauterine and post-natal infants (Leão da Silva et al., 2012). Furthermore, leptin levels have been linked to the risk for many cancers, such as prostate, lymphoma, ovarian, breast, and colon cancers, indicating that leptin plays a role in the development and progression of cancers (Shen et al., 2009). In some chronic diseases, the serum level of leptin is decreased because of fat mass loss of the cachexia caused by increased pro-inflammatory cytokines (Gulen et al., 2012). Some studies also identified the impact of leptin on respiratory diseases such as chronic obstructive pulmonary disorder, asthma, and lung cancer (Malli et al., 2010). Lower leptin serum levels were observed in NSCLC patients with cachexia, which was related to diminished fat mass (Ntikoudi et al., 2014). Lower leptin levels are often observed in advanced NSCLC patients with decreased body mass index values and increased pro-inflammatory cytokines, indicating the presence of malnutrition (Gulen et al., 2012). The decreased level of leptin does not result in cancer cachexia development, but is a result of cancer cachexia because of its dependence on body fat mass, which may increase food intake and decrease energy utilization to increase fat stores (Tas et al., 2005). Decreased serum levels of leptin are typically associated with advanced stages of NSCLC because of fat mass loss due to cachexia and increased pro-inflammatory cytokines. Accordingly, Alemán et al. (2002) found that the anorexia and cachexia of cancers are not due to dysregulation of leptin production, which is not increased in NSCLC patients with weight loss and is inversely linked to the inflammation response, which is only dependent on fat content.

To study the effect of other factors such as ethnicity, sample size, and detection method on the correlation between leptin serum level and NSCLC, a subgroup study based on these 3 factors was conducted. Ethnicity-stratified analysis showed that the significance of the relationship was affected in Asians and Caucasians. Larger sample sizes may influence the relationship between leptin serum level and NSCLC development, but a small sample size had no effect. In the analysis of detection methods, neither enzyme-linked immunosorbent assay nor immunoradiometric assay influenced the relationship, but the radioimmunoassay method had a significant influence. The relationship between lower serum level of leptin and the development of NSCLC has been confirmed in our analysis, which is in agreement with previous studies. The lower serum level of leptin may be a good biomarker for the development of NSCLC, particularly at advanced stages, which is important for differentiating NSCLC stages and the prognosis of NSCLC patients.

There were some limitations to our study. First, the 7 studies included a total of 705 cases; this sample size was not sufficiently large for comprehensive statistical analysis and may have resulted in statistical errors; particularly, follow-up testing may have been influenced. Second, although the serum levels of leptin were strongly correlated with sex, we did not exclude it effects 
in each subgroup in subgroup analyses. Specific gender-related studies are warranted to elucidate the exact role of leptin in the molecular mechanism of NSCLC. Furthermore, only tumor and healthy tissues were analyzed, which may restricted the reliability of this outcome. In this regard, a multiple blood test, urine-based, or stool-based tests should be conducted for these individuals, allowing for a direct comparison and combination of different test results. In addition, serum leptin levels were measured qualitatively in this study (high or decrease; positive or negative), which may have limited the quantitative data and restricted the present results. In this study, we collected baseline information at a single time point, but we did not perform serial measurements of this blood marker or other markers, limiting the use of our findings for broader applications.

In summary, we found that serum levels of leptin differed in NSCLC patients compared to in participants free of neoplasms. Based on our results, leptin may be a potential biomarker for the screening and prediction of NSCLC. However, the diagnostic performance of this single blood marker is simple and inconvincible than those of performance of combined detection of more useful biomarkers. Thus, using a combination of other serum markers with novel multiplex laboratory technologies requires further study to determine clinical performance.

\section{Conflicts of interest}

The authors declare no conflict of interest.

\section{ACKNOWLEDGMENTS}

Research funded by Technological Innovation Project of Young and Middle-aged Talents of Henan's Health Bureau. We would like to acknowledge the reviewers for their helpful comments on this paper.

\section{REFERENCES}

Al-Wadei HA, Al-Wadei MH and Schuller HM (2012). Cooperative regulation of non-small cell lung carcinoma by nicotinic and beta-adrenergic receptors: a novel target for intervention. PLoS One 7: e29915.

Alemán MR, Santolaria F, Batista N, de La Vega M, et al. (2002). Leptin role in advanced lung cancer. A mediator of the acute phase response or a marker of the status of nutrition? Cytokine 19: 21-26.

Ali Assad N and Sood A (2012). Leptin, adiponectin and pulmonary diseases. Biochimie 94: 2180-2189.

Alifano M and Damotte D (2013). Prognostic value of LIPC in non-small cell lung carcinoma. Cell Cycle 12: 543-544.

Bruno A, Chanez P, Chiappara G, Siena L, et al. (2005). Does leptin play a cytokine-like role within the airways of COPD patients? Eur. Respir. J. 26: 398-405.

Carpagnano GE, Spanevello A, Curci C, Salerno F, et al. (2007). IL-2, TNF-alpha, and leptin: local versus systemic concentrations in NSCLC patients. Oncol. Res. 16: 375-381.

Duan XY, Wang W, Wang JS, Shang J, et al. (2013). Fluorodeoxyglucose positron emission tomography and chemotherapyrelated tumor marker expression in non-small cell lung cancer. BMC Cancer 13: 546.

Ettinger DS, Akerley W, Bepler G, Blum MG, et al. (2010). Non-small cell lung cancer. J. Natl. Compr. Canc. Netw. 8: 740-801.

Ettinger DS, Akerley W, Borghaei H, Chang AC, et al. (2012). Non-small cell lung cancer. J. Natl. Compr. Canc. Netw. 10: 1236-1271.

Faggioni R, Feingold KR and Grunfeld C (2001). Leptin regulation of the immune response and the immunodeficiency of malnutrition. FASEB J. 15: 2565-2571.

Farooq R, Lutfullah S and Ahmed M (2014). Serum leptin levels in obese infertile men and women. Pak. J. Pharm. Sci. 27: 67-71.

Frühbeck G (2006). Intracellular signalling pathways activated by leptin. Biochem. J. 393: 7-20.

Gulen ST, Karadag F, Karul AB, Kilicarslan N, et al. (2012). Adipokines and systemic inflammation in weight-losing lung cancer patients. Lung 190: 327-332. 
Higgins JP and Thompson SG (2002). Quantifying heterogeneity in a meta-analysis. Stat. Med. 21: 1539-1558.

Jamieson NB, Brown DJ, Michael Wallace A and McMillan DC (2004). Adiponectin and the systemic inflammatory response in weight-losing patients with non-small cell lung cancer. Cytokine 27: 90-92.

Karapanagiotou EM, Dilana KD, Gkiozos I, Gratsias I, et al. (2011). Metastin is not involved in metastatic potential of non-small cell lung cancer. Med. Oncol. 28: 559-564.

Lago F, Dieguez C, Gómez-Reino J and Gualillo O (2007). Adipokines as emerging mediators of immune response and inflammation. Nat. Clin. Pract. Rheumatol. 3: 716-724.

Lang K and Ratke J (2009). Leptin and Adiponectin: new players in the field of tumor cell and leukocyte migration. Cell. Commun. Signal. 7: 27.

Leão da Silva P, de Mello MT, Cheik NC, Sanches PL, et al. (2012). Reduction in the leptin concentration as a predictor of improvement in lung function in obese adolescents. Obes. Facts 5: 806-820.

Looyenga BD, Hutchings D, Cherni I, Kingsley C, et al. (2012). STAT3 is activated by JAK2 independent of key oncogenic driver mutations in non-small cell lung carcinoma. PLoS One 7: e30820.

Lu X, Yang X, Yang Y, Gu X, et al. (2012). [Evaluation of serum cytokines in small cell lung cancer and its clinical significance]. Zhongguo Fei Ai Za Zhi 15: 11-16.

Malli F, Papaioannou Al, Gourgoulianis KI and Daniil Z (2010). The role of leptin in the respiratory system: an overview. Respir Res. 11: 152.

Molina JR, Yang P, Cassivi SD, Schild SE, et al. (2008). Non-small cell lung cancer: epidemiology, risk factors, treatment, and survivorship. Mayo Clin. Proc. 83: 584-594.

Ntikoudi E, Kiagia M, Boura P and Syrigos KN (2014). Hormones of adipose tissue and their biologic role in lung cancer. Cancer Treat. Rev. 40: 22-30.

Peters JL, Sutton AJ, Jones DR, Abrams KR, et al. (2006). Comparison of two methods to detect publication bias in metaanalysis. JAMA 295: 676-680.

Shen Y, Wang Q, Zhao Q and Zhou J (2009). Leptin promotes the immune escape of lung cancer by inducing proinflammatory cytokines and resistance to apoptosis. Mol. Med. Rep. 2: 295-299.

Song F and Gilbody S (1998). Bias in meta-analysis detected by a simple, graphical test. Increase in studies of publication bias coincided with increasing use of meta-analysis. BMJ 316: 471.

Song CH, Liao J, Deng ZH, Zhang JY, et al. (2014). Is leptin a predictive factor in patients with lung cancer? Clin. Biochem. 47: 230-232.

Tas F, Duranyildiz D, Argon A, Ŏguz H, et al. (2005). Serum levels of leptin and proinflammatory cytokines in advanced-stage non-small cell lung cancer. Med. Oncol. 22: 353-358.

Terzidis A, Sergentanis TN, Antonopoulos G, Syrigos C, et al. (2009). Elevated serum leptin levels: a risk factor for non-smallcell lung cancer? Oncology 76: 19-25.

Thomas T, Burguera B, Melton LJ 3rd, Atkinson EJ, et al. (2000). Relationship of serum leptin levels with body composition and sex steroid and insulin levels in men and women. Metabolism 49: 1278-1284.

van den Borst B, Souren NY, Loos RJ, Paulussen AD, et al. (2012). Genetics of maximally attained lung function: a role for leptin? Respir. Med. 106: 235-242.

Vernooy JH, Drummen NE, van Suylen RJ, Cloots RH, et al. (2009). Enhanced pulmonary leptin expression in patients with severe COPD and asymptomatic smokers. Thorax 64: 26-32.

Vernooy JH, Bracke KR, Drummen NE, Pauwels NS, et al. (2010). Leptin modulates innate and adaptive immune cell recruitment after cigarette smoke exposure in mice. J. Immunol. 184: 7169-7177.

Vernooy JH, Ubags ND, Brusselle GG, Tavernier J, et al. (2013). Leptin as regulator of pulmonary immune responses: involvement in respiratory diseases. Pulm. Pharmacol. Ther. 26: 464-472.

Walker S (2008). Updates in non-small cell lung cancer. Clin. J. Oncol. Nurs. 12: 587-596.

Yingzhong Y, Droma Y, Rili G and Kubo K (2006). Regulation of body weight by leptin, with special reference to hypoxiainduced regulation. Intern. Med. 45: 941-946.

Zintzaras E and loannidis JP (2005a). HEGESMA: genome search meta-analysis and heterogeneity testing. Bioinformatics 21: 3672-3673.

Zintzaras E and loannidis JP (2005b). Heterogeneity testing in meta-analysis of genome searches. Genet. Epidemiol. 28: 123-137. 